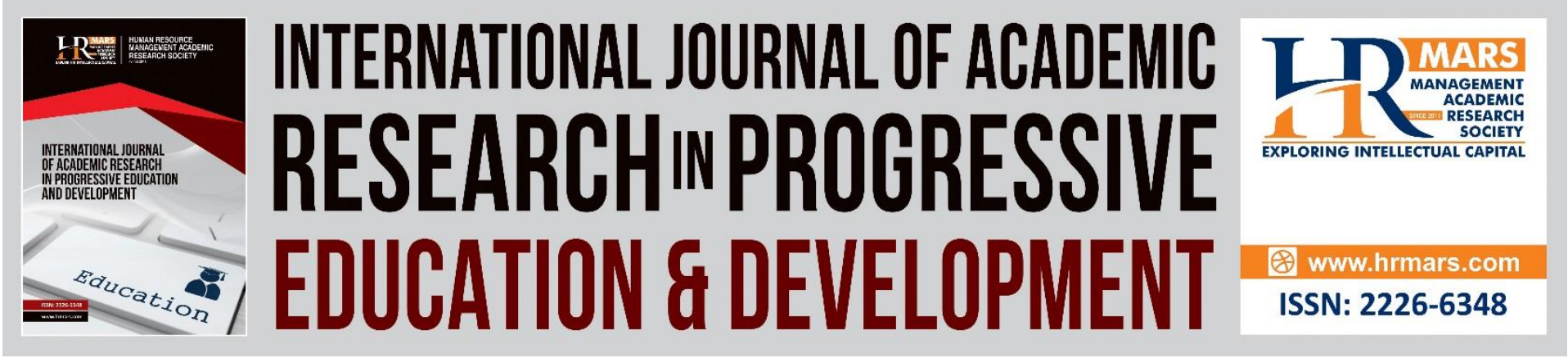

\title{
Difficulties Faced by Non-Native Translators in Translating Figurative Local Libyan Language to English
}

Lutfi Mohammed Mohammed Alhemmair Alwash, Muhammad Alif Redzuan Abdullah

To Link this Article: http://dx.doi.org/10.6007/IJARPED/v11-i1/11174

DOI:10.6007/IJARPED/v11-i1/11174

Received: 01 December 2021, Revised: 03 January 2022, Accepted: 25 January 2022

Published Online: 14 February 2022

In-Text Citation: (Alwash \& Abdullah, 2022)

To Cite this Article: Alwash, L. M. M. A., \& Abdullah, M. A. R. (2022). Difficulties Faced by Non-Native Translators in Translating Figurative Local Libyan Language to English. International Journal of Acdemic Research in Progressive Education and Development, 11(1), 1003-1018.

Copyright: (C) 2022 The Author(s)

Published by Human Resource Management Academic Research Society (www.hrmars.com)

This article is published under the Creative Commons Attribution (CC BY 4.0) license. Anyone may reproduce, distribute, translate and create derivative works of this article (for both commercial and non-commercial purposes), subject to full attribution to the original publication and authors. The full terms of this license may be seen

at: http://creativecommons.org/licences/by/4.0/legalcode

Vol. 11(1) 2022, Pg. 1003 - 1018

Full Terms \& Conditions of access and use can be found at http://hrmars.com/index.php/pages/detail/publication-ethics 


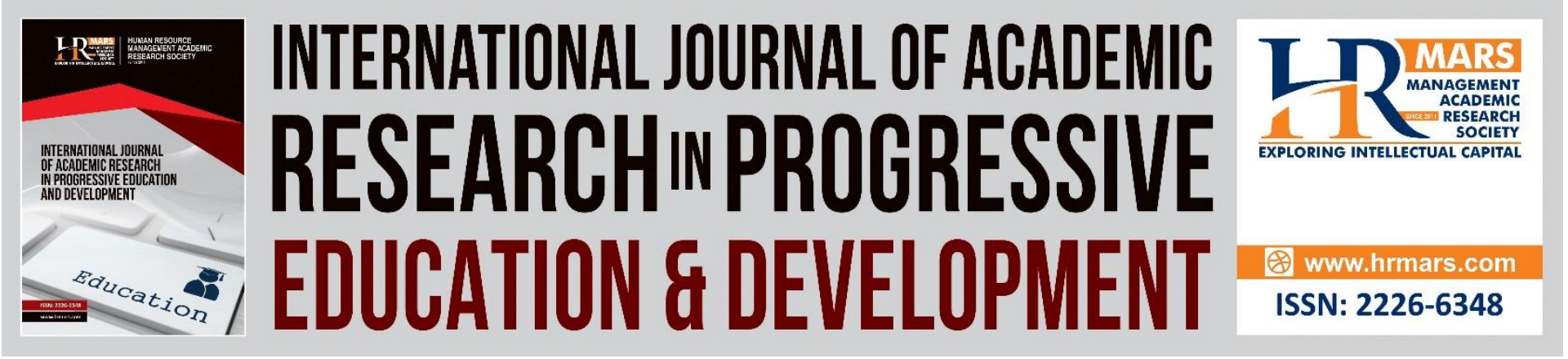

\title{
Difficulties Faced by Non-Native Translators in Translating Figurative Local Libyan Language to English
}

\author{
Lutfi Mohammed Mohammed Alhemmair Alwash, Muhammad \\ Alif Redzuan Abdullah \\ Faculty of Modern Languages and Communication, University Putra Malaysia. Selangor, \\ Malaysia \\ Email: gs55582@student.upm.edu.my,muhammadalif@upm.edu.my
}

\begin{abstract}
This study aims to explore the obstacles when translating the figurative metaphor in vernacular Libyan Arabic language to the English language that was employed in the speech of the former Libyan President Al Ghaddafi in his last speech, and difficulties of understanding the meanings hidden in his figurative language that could be faced by Arabic language translators but Libyan translators who know more about their vernaculars spoken by Libyans. The objective of the study was to identify and analyze the obstacles in meaning for a literal translation of Al Ghaddafi's speech by focusing on words, not in meaning required by the speaker by ignoring the cultural contexts, with no focus on the lexicon used. The last speech was broadcast on Libyan TV on $22 \backslash 2 \backslash 2011$ before he was overthrown from power as a president of Libya. Nord's (1991) model of text analysis was used as a theoretical framework to analyze the obtained data. Nord's text analysis model consists of two main aspects: extratextual and intertextual factors. It gives a framework that allows both the source and potential target text to be analyzed. Both macro analysis (semantic macrostructures) and microanalysis (local semantics) were conducted. The results of the study revealed that this speech has its distinctive features, and that language was used delicately to arrive at the intended goals of the speaker. Furthermore, the result of the study revealed that the semantic phenomena employed has the correct effect of meaning not the literal meaning of the word, therefore, in the vernacular language of any language a strong cultural background shall be needed for any translator, and our example here in the Arabic language which has more than twenty vernaculars that are spoken by millions but in our example translating the meaning by a Moroccan or Iraqi translator will be a huge obstacle for him when translating a word by word meaning and leaving the semantic meaning of the word in the Libyan vernacular meaning that will mention as (LLL) Libyan Local Language.
\end{abstract}

Keyword: Al Gaddafi, Translation, Figurative Language, Local Libyan Language, Last Speech 


\section{Introduction}

In recent years, the Arabic language has suffered a great weakness, after it was one of the most powerful and important languages in the world and one of the most sought after. The fact that the Arabic language has been subjected and is still subjected to several violent attacks, comes to the forefront in our view of the tyranny of foreign languages, especially English and French. The second attack is embodied in the use of the vernacular, or what has become called by many recently "spoken Arabic", which has, in fact, turned into "Arabia" and not one Arab, as this calls itself Arabic. The Egyptian, the Algerian, and the other Kuwaiti or Moroccan, and so on, in a way that does not serve the unified language, as if Arabic had been transformed into a nationality after it was a universal language that did not divide its Arab and Islamic nation.

Translation errors are not always that comic and being funny will not explain them. It may just make things worse. Language Variation: classical standard Arabic or the language of Quran is the language studied in learning institutions but not the language is spoken in the Arab countries. Each Arab country has its own words or identity which little bit different from not only the neighboring country but from the far Arab country (e.g.: Morocco and Iraq), this variation enriches the language with many borrowed words and each language has its own dialects and its own words. In media or in TV each country uses its Arabic local language that cannot be described as classical or standard Arabic. Translators from Arabic to English may face these obstacles when translating speeches of two different Arab nationalities at the same time. Therefore, the translator's cultural background is an important obstacle to those who translate a vernacular language out of their culture. This is the language variation in the Arabic language.

The Arabic Language is spoken by a significant percentage of the world's population. It is being used as means of communication among Arabs and non-Arab Muslims as well. This variation of the Arabic language led to a kind of independence of a vernacular language for each Arab country. An example for the word "too much" in English has a totally different word among them and even within the same country. From the classic, this word is said "katheran", in Morocco "Bezaf", in Tunisia "Barsha", in Egypt "Ekther", in Libya they use two for the same word "halba and waged". These are examples of this language variation and added more responsibilities on the Arabic language translators of other nationalities who studied classical Arabic. One of the difficulties they face is the translation of figurative metaphor and specifically if they were translating from vernacular discourse.

This paper will focus on the metaphoric figurative scenes in the last broadcasted speech he delivered on $22 \backslash 2 \backslash 2011$. That speech was full of such metaphors which will be hard for nonnative or translators with no background in Libyan culture. This paper is designed with a view to looking into the translation of figurative LLL problems of translating Arabic texts into English and fixing them with prospective and suitable meaning. As translation is a very sensitive and subtle task of language studies, it involves some serious issues to deal with. However, it becomes a more complex task when we translate from local (vernacular) Arabic to English. So, a translator must have critical linguistic knowledge in tackling both the surface and underlying meaning of language.

\section{Review of Related Literature}

Empirical evidence has revealed that researchers have different perspectives on the nonequivalence issue. For example, Kohil (2009) examined the problems of finding an equivalent in translating English idiomatic expressions into Arabic. In other words, she tried to 
understand how students' linguistic competence affects their translation performance. Twenty-five students in the English Department of the Mentouri University of Constantine were chosen randomly to complete a written translation test. The findings displayed that the errors made by the participants are more than their correct answers. They also revealed that participants face difficulties when translating idiomatic phrasal verbs from English into Arabic. The primary reasons of the participants, ' difficulties are related to their limited linguistic competence.

Khammyseh (2015), likewise, examined the problems that face M.A translation students in translating Islamic expressions in religious occasions from the Arabic language into the English language. The findings showed that there are some difficulties that face M.A translation students in translating some Islamic expressions used by Jordanians on religious occasions. These difficulties were mainly related to the differences between both languages styles and the lack of equivalences in the target language (English). The researchers concluded that the reasons that cause these problems were the lack of experience in the culture of the target language and the lack of knowledge in both languages' structures.

Moreover, Alrishan \& Smadi (2015) examined the difficulties that Jordanian EFL university students face in translating English idioms into Arabic. Ninety M.A translation students were asked to translate sixteen idioms. The findings showed that M.A students have difficulty in translating opaque and semi-opaque idioms.

Paraphrasing was used as a strategy to give the meaning of these idioms. The researcher concluded that students demonstrated problems in rendering English idioms into their Arabic cultural equivalents; this is due mainly to their poor pragmatic competence in the target language (English).

Furthermore, Bani-younes (2015) investigated the problems that face students in translating collocations. In order to observe these problems, a questionnaire was given out to $40 \mathrm{MA}$ students majoring in the English Language.

The findings showed that participants faced several cultural and sociolinguistic problems, such as the word order within the same collocation, the linguistic issues related to religious words, and the availability of acceptable equivalents in the target language. The findings also revealed that participants had not adequate proficiency in collocations.

Finally, Yousefi (2017) focused on translation quality assessment, especially addressing the problems in translating religious texts. In order to achieve the aim of the study, the researcher chose Waddington's model for evaluating the quality of translations; to find if the quality of translations of Islamic texts which were translated by Muslim translators were higher than those which were translated by non-Muslims. The study concluded that there was no relation between the religious beliefs of translators and the quality of translations.

Looking back into these studies, the researchers noted that most of these studies are devoted to examining either the students' ability in translating idiomatic expressions from English into Arabic (e.g., Ali, Al-Rushaidi, \& Mohammed, 2017; Alrishan \& Smadi, 2015; SajidJuma'a, 2014), or to explore the problems that face students in translating some Islamic expressions from Arabic into English (e.g., Dweik \& Suleiman, 2013; Khammyseh, 2015).

However, little effort has been made to examine and little attention has been paid to investigate in translating social-cultural concepts from the Arabic language to the English language. This study will therefore bridge this literature gap. The present study deals with figurative metaphors used by Al Ghaddafi at the semantic level that has not been discussed widely in the previous studies related to daily life expressions. Reviewing the abovementioned studies helped the researchers to decide the methodology of the present study. 
DEVELOPMENT

Vol. 11 , No. 1, 2022, E-ISSN: 2226-6348 @ 2022 HRMARS

\section{Statement of the Problem}

Ebtesam Mokhtar a native Arabic translator living in Egypt. Wrote an article on an internet site (https://www.smartling.com) titled "Four Things That Make It Difficult to Translate between English and Arabic" she stated in her article four obstacles in translating texts from English to Arabic:

a- Cultural differences: One of the most interesting things about translation is that it makes people open to different cultures. For Arab translators, this is an expensive pleasure. Sometimes, a single English word cannot simply replace an Arabic one. Alternatively, the translator may need to explain the meaning of the Arabic word using one or more sentences in English. This happens frequently when working on Islamic terms. For example, "Hoor AlAyn" is an Islamic concept in which "Hoor" is the intense whiteness and deep blackness of the eye, and "Al-Ayn" means "eyes." The whole term ("Hoor Al-Ayn") refers to pretty virginal women with beautiful eyes who will be a reward for martyrdom or doing good works in life. Here, the translator's job is not limited to interpreting the meaning literally but to explaining what facts are behind it. It is said that Arabic is an emotional language. While it may be a "fertile" language, a 2,000-word Arabic document can be translated into just 1,500 English words. This happens because the Arabic language has many ways to convey the same meaning. Different words with the same meaning can be used to "intensify" an idea, usually making sentences longer.

b- Differences within Arabic Culture Itself: According to Ms. Irina Bokova, Director-General of UNESCO, Arabic is a language with more than 422 million speakers in the Arab world and is used by more than 1.5 billion Muslims. However, if you hear how Arabic is pronounced in different Arab countries, you may think that they are speaking different languages. Dialects may even vary within the same country. In Egypt, Cairo residents say "fetert" ("I ate my breakfast") while people in the province of Alexandria pronounce this "fatart." Regardless of the pronunciation, this word is slang. Arabic translators should be aware of all of these differences when carrying out their projects.

c- Arabic Letters with No Equivalents in English: The Arabic alphabet consists of 28 letters. At first glance, this does not seem very different from English, which includes 26 letters, but the reality is quite the opposite. There are some Arabic letters that have no equivalent in English. Many foreign Arabic learners remain unable to pronounce these letters because some of them have special tones that are not found in any other language. Examples include $(\dot{\varepsilon})$, which is substituted by (gh), and $(\dot{\tau})$, which is replaced by (kh). This makes it difficult to write Arabic names precisely in English letters. For example, let's back to the name of the writer mentioned at the beginning of this article: Fatma Naaot. The section "aa" is the standard attempt to make the double (a) sound like the Arabic letter $(\varepsilon)$. However, the letter $(\varepsilon)$ is emitted from a deeper place in the mouth than the English equivalent (aa). English alternatives are out there, but most of them have different articulation points than the original Arabic letters. Translators just have to pick the letters that best resemble the sounds of the Arabic ones.

d- Having to Shift the Way of Thinking: This difficulty is felt more by native Arabic translators. They are used to thinking in their native language, but they have to switch to the "English way of thinking" when translating between English and Arabic. Phrasal verbs are the perfect example. In English, the sentence "I think of/about something/someone" would translate most closely into Arabic as "I think in something" or "I think by someone." Similar confusion reigns when translating the sentence "I am thinking of my new wardrobe, I really like it!" 
Arabic use of prepositions would make this "I am thinking in my new wardrobe, I really like it!".

e- The danger of colloquialism on the Arabic language: Among the dangers facing Arabic is also the danger of colloquialism, which has been replacing Arabic In fact, the Arabic language has transformed from a language in which written and spoken are equal, as in the eras of its prosperity in the pre-Islamic and Islamic eras until the second Abbasid era, in which cultures overlapped, to a language written in one form and spoken in another way, and the great danger lies in the colloquial In converting the Arabic language from the language of unifying the Arab nation into a language of division, as there has become what is called Egyptian, Moroccan, Emirati, Algerian, Tunisian, Kuwaiti and Jordanian, and thus instead of one unified word, Arabic, and the conflict between these colloquial Arabs has intensified to an extent. The desire of each to impose his slang from the other in many ways, we mention them, especially cinema and the so-called art "singing". The Algerian worked hard to insert "Bazaf", the Tunisian worked hard to include "Barsha" and the Libyan one to use "Yasser", everyone wanted to express the written Arabic word "much" or the Arabic of the book as it became called due to the abandonment of its use for communication, at least, until Oud intensified. colloquial and became blocks of blocks i.e. Maghreb illiteracy as a bloc, Gulf colloquial as a second bloc, Egyptian as a third bloc, Egyptian as a fourth bloc, and so on... to the extent that what has become called spoken Arabic appears, which does not coincide, but rather repels, day after day, more than written Arabic, to the point that foreigners are now unanimously agreed that it is no longer there is no communicative benefit from learning Arabic in universities and schools, because Arabic is what we learn in universities Schools are Arabic only, books are not communicative in society, and if they are valid in a scholarly Arab society, they are not valid in another society.

f- Effects of colloquial use in the Arab world: Among the most important and worst effects of colloquial use in the Arab world, or rather colloquial or spoken Arabic, is the great rift between that Arabic that we write and read and that we communicate with here and there, which made the Arab or the foreigner He does not strive to learn it for anything other than a religious purpose, because it is no longer a private process in the eyes of the foreigner, who learns it and then does not benefit from it, unlike, for example, French or English.

Among its effects, too, is the rumor and spread of melody in written Standard Arabic, that is, the entry of hybrid and strange structures into Arabic, whose source is colloquial thinking and expression in Arabic, which results in weak Arabic, which may be transmitted over time, especially through the media, to become a bitter reality, contaminated Arabic. We do not know why. It may be interpreted in the future, but the least of what it comes to Arabic is polluted, weak, and outside the rules and norms that bind the Arabic language, and it may originally depart from its original genius, which usually results from a bad translation from colloquial into Arabic, weakening its level and destroying its eloquence and even its eloquence. And in light of these dangers facing the Arabic language from foreign and colloquial languages, in a diverse world Languages and cultures. Some see that the translation movement may be an escape from the criticism of the Arabic language, if only partially, from the set of dangers facing it.

\section{Research Objectives}

The objective of this study is to do a critical discourse analysis of AL Ghaddafi's changing stances through applying content analyzing theory in his speeches. The study is set to achieve specifically, the following objectives: 
DEVELOPMENT

Vol. 11, No. 1, 2022, E-ISSN: 2226-6348 @ 2022 HRMARS

1. To identify the lexical categories in AL Ghaddafi's speech shows figurative metaphors using the speech textual elements.

2. To analyze the figurative metaphors in Al Gaddafi's speech.

3. To summarize the figurative metaphors in AL-Gaddafi speech.

\section{Research Questions}

This paper aims to answer the following research questions:

1. What semantic problems in vernacular language do translators face when translating figurative expressions from the Arabic language into the English language?

2. What are the reasons that cause these problems?

\section{Significance of the Study}

To the best knowledge of the researchers, there are few researchers that have semantically studied the translation of cultural expressions in the Arab world. Much of the research to date has been done where most of the attention has been on specific language constructs like idioms, proverbs, and collocations. Thus, this study tries to fill what appears to be a gap in translation literature. The findings of this paper will help and may provide additional suggestions when they come across such cultural expressions. The role of cultural differences is also considered in this study as one of the most important factors to be considered in the translation process. The translators should know the source language culture and the differences between the two languages to reflect the culture properly. They need to be aware of the fact that translation is not only a matter of transfer but also a place where cultures unite. The outcomes of the study are expected to contribute significantly to the field of translation in general and translating vernacular languages in particular. The study seeks to benefit student translators who intend to study translation at the university level. It is also of benefit for new researchers in translation as it would be one of the first recent studies to discuss figurative vernacular language related to Al Ghaddafi. The results will also familiarize those new researchers with strategies and techniques used in translating collocations based on the experiences of professional translators.

\section{Justification of the Study}

The present study sheds light on the problem of translating figurative images in vernacular speeches from a translator's perspective rather than from didactic perspectives. The beneficiaries from this study are professional translators, novice translators, and student translators who usually lack the experience to deal with these translation issues.

The researchers are trying to focus on the different strategies usually used in translating those collocations. In the present study, extracts of figurative images from Al Ghaddafi's speech are expected to be translated from Local Libyan Language to English and what non-Libyan cultural background may think of the translation of such words.

\section{Language and Culture}

It has been seen that language is much more than the external expression and communication of internal thoughts formulated independently of their verbalization. In demonstrating the inadequacy and inappropriateness of such a view of language, attention has already been drawn to the ways in which one's native language is intimately and in all sorts of details related to the rest of one's life in a community and to smaller groups within that community. This is true of all peoples and all languages; it is a universal fact about language. 
Anthropologists speak of the relations between language and culture. It is indeed more in accordance with reality to consider language as a part of the culture. Culture is here being used, as it is throughout this article, in the anthropological sense, to refer to all aspects of human life insofar as they are determined or conditioned by membership in a society. The fact that people eat or drink is not in itself cultural; it is a biological necessity for the preservation of life. That they eat particular foods and refrain from eating other substances, though they may be perfectly edible and nourishing, and that they eat and drink at particular times of day and in certain places are matters of culture, something "acquired by man as a member of society," according to the classic definition of culture by the English anthropologist Sir Edward Burnett Tylor. As thus defined and envisaged, culture covers a very wide area of human life and behavior, and language is manifestly a part, probably the most important part, of it.

Although the faculty of language acquisition and language use is innate and inherited, and there is legitimate debate over the extent of this innateness, every individual's language is "acquired by man as a member of society," along with and at the same time as other aspects of that society's culture in which people are brought up. Society and language are mutually indispensable. Language can have developed only in a social setting; however, this may have been structured, and human society in any form even remotely resembling what is known today or is recorded in history could be maintained only among people utilizing and understanding a language in common use. (Crystal et al., 2020). Language. Encyclopedia Britannica.

https://www.britannica.com/topic/language)

\section{Metaphor Theories}

The development of metaphor theory begins with Aristotle's Poetics and Rhetoric and Quintilian's textbook on rhetoric, Institutio Oratoria, passing through semantics and reaching philosophy, scientific discourse, and cognitive linguistics. According to Ricœur (1977), this progression through the disciplines is complemented by an analogous itinerary from wordunit, to sentence, to discourse. Classical rhetoric defines metaphor as a single-word figure of speech and describes it in terms of deviation. Metaphor is a group of resemblances operating spatially through displacement and transportation. The early rhetorical understanding of metaphor led to the formation of a substitution theory that relegated the role of metaphor to that of a mere ornament and assumed that metaphors can be completely retranslated into figurative meaning.

A radical reinterpretation of metaphor was introduced by Nietzsche, who defined truth as "a movable host of metaphors [and] metonymies" (1999:84), suggesting that our very grasp on truth was pre-structured by language and its operative principles. In the Philosophy of Rhetoric, first published in 1937, Richards abolishes the clear-cut border between the literal and the figurative and introduces the interrelated notions of tenor and vehicle. The tenor refers to an object, person or idea, and the vehicle is that to which the tenor is compared. The copresence of tenor and vehicle and their interaction generate the meaning(s) of the metaphor.

Metaphor is no longer a simple transfer of words, but a transaction of semantic contexts (Richards, 1965). Following in Richards' footsteps, Black (1954) draws a distinct boundary between the classical theory of metaphor and what he terms the interaction view. He describes the structure of metaphorical statements, which consist of a focus (one or more words considered metaphorical) and a frame (the non-metaphorical context of the 
statement). Meaning arises from the interaction of frame and focus. The frame of the metaphor acts on the focal word to produce new meaning, which is not reducible to a simple paraphrase or literal use. In a subsequent essay, Black (1962) reinterprets metaphors in terms of models, highlighting the connection between their descriptive and heuristic functions. Metaphors and models possess a common isomorphic structure and function through complex networks of statements.

This new interpretation liberates metaphor from its confinement to rhetorical and linguistic understanding and significantly narrows the distance between the humanities and the natural sciences, both "an affair of the imagination" (ibid.:242). Black's view bridges the gap between earlier semantic accounts and the upcoming radical extension of the meaning of metaphor in scientific theory and cognitive linguistics.

Metaphor is a language and idiomatically a metaphor in the language is the lifting of a thing and its transformation from one place to another, such as saying: I borrowed something from so-and-so, that is, I transferred it from his hand to mine, as for idiomatically, it is one of the sciences of rhetoric related to the science of rhetoric, one of the branches of rhetoric science, which was defined by many writers and rhetoricians. Statements regarding what is related to it are summarized in that it is the use of a word or meaning other than what it was placed in or it came to him because there is a similarity between the two words.

\section{How is Figurative Language Used?}

Figurative language is used in both literature and poetry to create layers of meaning accessible to the reader through the senses, symbolism, and sound systems. Figurative language makes the reader more in-depth on the topic of the work, without the author having to explicitly place the characteristic of the reader. It is a way for the reader to enter words with their minds and emotions, rather than just understanding a story or poem. The metaphorical language encourages the reader to make connections with the characters, the plot, and the deeper message of the work that creates the most memorable experience for the reader. There are several types of figurative language, but the most common are: 1- simile 2- A false similarity 3- embodiment 4- Symbolism 5- hyperbole 6- Photographer 7- Sophistry contradictory speech 8-The paradox 9-Voice Simulation 10- Mono quote.

\section{Background of the Study}

After the military coup in 1969, a young military officer with nationalist and pan-Arabic aspirations, Al Ghaddafi, came to power, changing the fate of the country for over four decades. Under his rule, the social welfare of the Libyan people increased quite dramatically thanks to the oil revenues, yet they were deprived of true freedom due to the implementation of Ghaddafi's most famous Green Book, embracing a theory in between communism and Islam, namely „Third Universal Theory". By challenging the Western countries, particularly the US in Middle Eastern politics and France in Africa, Ghaddafi's grand aspirations to become a leader of the Arab states, following in Nasser's footsteps, and then "the king of kings" in Africa made him the object of dislike not only by the Western countries but also by leaders in the Middle East and Africa. Nevertheless, his true isolation came with the imposition of multilateral sanctions upon his country in 1992 for his sponsorship or suspected sponsorship of terrorism.

Al-Ghaddafi was marked as one of the strangest leaders and of giving long speeches in LLL and his speeches were always full of idioms and figurative that found difficult to be translated literally and translators must deal with the word intended meaning, not the lexical meaning. 
Therefore, translators used to deal with the meaning when translating their speeches and this will be difficult for different background translators. This article tries to look at the figurative words found in his last speech and to explain the meaning of figurative words used in both the lexical and intended meaning.

\section{Research Methodology}

The main purpose of the present study is to investigate the difficulties of subtitling from Arabic vernacular (LLL) into English. With the help of linguistic features of discourse and generated social background of specific events, and to accomplish the purpose of the study and obtain a precise and pertinent conclusion, the researchers used the content-analytical approach. The present research tried to fill the gap in the field of translating figurative in Libyan vernacular particularly political collocations and cast the light on the different translation strategies used in translating the collocations rather than mentioning the problems and setting some solutions. The findings are expected to add significantly to the field of translating collocations since translators confirmed that translation is a unique task for any interested person not necessarily to be a translator while translating collocations is a sensitive field and choice. After the end of his era, most if not all his documented speeches or written papers were destroyed by people during the early days of the revolution.

The data sample shall be samples of the strangest found speeches Al-Ghaddafi delivered and documented in crucial dates that affected the state relations. In translation studies today, we have a master narrative of the translator as an honest intermediary, with translation repeatedly portrayed as a force for good, a means of enabling dialogue to take place between different cultures and therefore (the logic goes) improving the ability of members of these different cultures to understand each other. Accordingly, communication, dialogue, understanding, and indeed knowledge are assumed to be 'good' in a moral sense. They lead - unproblematically - to justice, peace, tolerance, progress. This shall be the theory to be followed in this paper, the theory developed by Baker. Narrative Theory as developed by Baker will specifically focus on the selective appropriation approach. Baker's understanding of the role political narratives play in the context of translated discourse will help reveal some common narratives of the Arab Spring in Arabic and English. Narrative Theory as developed and advanced by Baker will be applied to understand how these speeches were interpreted through the dominant narratives and whether they were eventually affected by existing narratives.

Thus, Baker highlights that it is a complex process to retell a story told in one language into another, saying "the retelling is inevitably constrained by the shared linguistic and narrative resources available in the new setting" (Baker, 2006: 29). Baker illustrates that metanarratives can exist in different versions and are subject to disputation just like any other type of narrative, and are able to cross different boundaries and become internationally known. The factors that help sustain certain meta-narratives are usually economic or political factors. Translators have an undeniable role in allowing public narratives to cross the linguistic boundaries and develop into widespread meta-narratives (Baker, 2006:45-48). A representative example for a metanarrative from the Arab Spring is the public narrative of NATO's intervention in Libya, which would not have been possible if it had not been preceded by the circulation of a meta-narrative on the horrifying massacres and the brutal killings of civilians by Al Ghaddafi's regime. For this research, drawing on Baker's narrative theory will allow me to examine to what extent the media changes certain narratives or bases them on 
existing ones. This should be achieved by considering the shared narrative and how it affects the way people perceive the world.

\section{Lexical in Al Ghaddafi Speeches that Show Figurative Messages}

Metaphor and politics, Metaphors are an indirect, non-literal language. They are used to saying something but mean something else. They are usually quite problematic and difficult. A metaphorical translation involves the translation of SL metaphors into TL metaphors. In creative metaphors, the vehicle (i.e. the form) and the tenor (i.e. the content) become intertwined and subsequently inseparable. However, metaphors are not always creative; they are frequently used as decorative. Every follower of political language will notice that it is examined and borrowed from all fields and fields to find the necessary political significance when dealing with a specific issue or problem, whether of international concern or an internal public interest. Thus, we will find that political language and political discourse deal with all fields, without exception, and the evidence is that political language and political discourse were never a pure descriptive language, otherwise it is possible today, with the advancement of media women, to replace them with symbols, and translate them automatically in the computer. But the language of politics and political discourse has always and always been a multi-level and reference language. It is a language in which description is mixed with evaluation, codification of the matter, and monitoring with a recommendation.

Al Ghaddafi used the pronoun (I) about 105 times during his Zangha Zangha speech on $22 \backslash 2 \backslash 2011$, to reflect on his success and to revolve the speech around him. An example is illustrated below:

"I am higher than the positions that presidents and pomps take, I am a fighter, struggler, warrior, and revolutionist, from the tent, from the desert".

Ana arfa'o men almanasib allati yatakaladha alroasa wa al obahat, ana mokatil, mojahid, monadhil, tha'ir men al Khaimah men al badia.

أنا أرفع من المناصب التي يتقلدها الرؤساء والأبهات، أنا مقاتل، مجاهد، مناضل، ثائر، من الخيمة، من البادية

In this example, the 'l' was followed by several active participles, which are usually used as an adjective or a descriptive term in Arabic. The English equivalent of it would usually be a noun ending in /-er/ or /-or/, for example fighter (Ryding, 2005: 103). Al Ghaddafi described himself using his favorite active participles that have always been associated with his name:

fighter, struggler, warrior, revolutionary, from the desert.

Mokatel, mogahid, monadhil tha'ir men al khiemah.

ثائر، من الخيمة

It would not be an exaggeration to say that in the future hall of shame that Al Ghaddafi's name would surely make the top ten list of dreaded dictators that sojourned this earth. Names like Benito Mussolini of Italy, Saddam Hussein of Iraq, Emperor Hiro Hito of Japan, Adolph Hitler of Germany, Joseph Stalin of USSR, Idi Amin of Uganda, Sani Abacha of Nigeria, etc. would also make the top ten list. And finally, we should not see the reign of Ghaddafi as beneficial to mankind. I heard somebody say he started well but ended so badly. In leadership, one should start well and finish well. I urge our leaders to learn a big lesson from Al Gaddafi's demise.

Thousands of political terminologies and phrases can be found in lexicons, one of the phrases that continue to excite me is Algerdan "Rats". I must confess that the killing of Muammar Gaddafi of Libya made me be obsessed with the phrase. Not even the legendary Bob Marley and the musical lyrics on Rat Race in one of his hits could make the phrase Algerdan "Rats" 
create a lasting impression in my subconscious or inspire me to go onboard on an etymological journey in search of the relevance of the phrase in global politics.

When the widely publicized uprising in Libya against the tyrannical government of the late Gaddafi was at its apogee, Gaddafi, in his unflappable mannerism, for the umpteenth time called the people that took their protests to the streets and squares. He once issued a command that his loyalists should kill the Rats (the protesters) without fear or kindness. I watched him on the television screaming that the Rats should be killed. It is the height of arrogance for a leader to command his loyalists to kill those protesting against his tyrannical government.

Given the unbridled obsession for Rats which Algerdan "Rats", as I funnily and mockingly called him, exhibited during the uprising that eventually consumed him and put an end to his tyrannical government, I made reference to my dictionary and found out that the phrase Algerdan "Rats" simply means undignified competition for success in one's career, social status. Further reference to the dictionary revealed that in a figurative sense it means a person who deserts a cause. (This emanates from the belief that rats desert a ship that will sink or be wrecked).

Having satisfied my intellectual curiosity about the lexical meanings of rats and rat race, I deduced from my findings that Rat is a politician. If there is anything, I would remember Gaddafi for, it is the addition of a new idiom contribution he made towards the development of the world's political jargon. Naturally, Rat is a rodent. According to the dictionary, a rodent is an animal, e.g. a rat, rabbit, squirrel, or beaver, which gnaws things with its strong teeth specially adapted for this purpose. Rat is destructive by nature. If rats invade a farm, the crops in that farm are bound to be completely destroyed in a few hours by the rats. Figuratively put, are politicians all over the world not destroying the sustaining resources of their respective countries? As rats would do to the farms, many countries in the world have been impoverished by politicians so much that one would not be wrong to unequivocally say that politicians are rats.

Given the foregoing definition, it is no more news that politicians all over the world are always engaged in ceaseless and undignified competition for victories during any election. Politicians do not accept defeat even when it is very obvious that they failed. They are always engaged in power struggles, and I have seen rats behave the same way. I have seen rats struggle over a piece of bread or the like. Their struggles are always reminiscent of that of politicians struggling for power.

\section{Conclusion, Discussion \& Findings in Al Ghaddafi Speech}

The cultural background of a translator is a very important issue in translation that entities and governmental authorities must consider in choosing the right ones in accordance with their guests' origins. Al Ghaddafi's speech was in LLL and was full of sarcasm and it is obvious for translators that sarcasm is a sharp, bitter, or cutting style of expression that usually means the opposite of its literal phrasing. Sarcasm frequently loses its meaning when translated word-for-word into another language and can often cause unfortunate misunderstandings. Ideally, a translator could remove sarcasm from the source text prior to translation. But in cases of translating a speech that way, translators of no background of the speaker's culture will have sometimes no chance to avoid literal misunderstandings, but those who have a cultural background will suggest a local idiom which has the meaning that may work better in the target language. 
Political terminology has always posed a fundamental dilemma in international relations, political councils, national conflicts, regional conflicts, and others. These activities and events have always highlighted the great gap that exists between human languages, general civilizations, and individual cultures. Through translation, the dimensions of the human understanding of many aspects of the language, whether original or additional, are immediately apparent, and one's ability to encompass many aspects of its uses that change from reality to reality and from generation to generation becomes apparent, so it takes on general collective or individual meanings and shades of the meanings have nothing to do with the original meanings.

In the world of politics and the media, translation occupies a large and important place in conveying the news from the heart of the event, and sometimes even in its fabrication. The influential great powers have always relied on the media to promote certain policies and ideologies, to incite public opinion, and to impose civilizational and linguistic hegemony, either through changing and altering individual and collective attitudes or by forming new positions on certain matters, situations, and affairs. Persuasion techniques differ in the different uses of directed media, as detailed by J. Brown in his famous reference book "Methods of persuasion: from propaganda to brainwashing", from the use of what has become known today in Arabic as stereotypes and the display of characteristics and characteristics of certain real or false and exaggerating them among individuals and groups, and even removing human characteristics from them, and adopting vocabulary Alternative negative or positive expressions charged with emotion to replace neutral, objective, and selective expressions in highlighting facts or what is known as fragmentation of truth or fragmentation of reality, lying, repetition, assertion, identifying the enemy and diverting anger and hostility towards him, and resorting to power without specifying its sources (and experts in science said Genetics Arabs are by nature prone to violence and terrorism.

Ali Darwish, Professor of Translation and Technical Communication at the Universities of Melbourne, Australia, and an author and technical writer, wrote an article in the Arabic language titled "The Crisis of Translation and Self-Censorship in Arab Satellite Channels and the New Arab Media School" in Al-Manakh newspaper (Australian newspaper in Arabic), I choose from him the following:

"The term separation wall, fence, and fence between fence and wall. Sometimes it is the separation wall, to ensure the neutrality of the Arab media in reporting the news, as they claim, and sometimes it is the apartheid wall. The strange thing about these options is that the word (fence) in the English language is worse than the wall. Fencing in English (fence) is often used to prevent livestock and animals from entering a certain area or to contain them in a fenced enclosure, towards (fence off wild animals) and (fence in goats and sheep), or to ward off potential danger. The fence also does not have a permanent character, as a storm or whirlwind may blow it and destroy it or uproot it from its foundation, or its owner may remove it because the need for it will no longer be necessary. The wall is stiffer and more durable than the fence. The insistence of the Arabs, media professionals, and politicians, to use the "separation wall" as neutrality and the "Apartheid Wall" as an analogy to the Berlin Wall, drops these negative and temporal meanings that the word "fence" has in English. On the one hand, we find the separation wall for the Palestinian people".

The correct word should be chosen in all languages and the above-stated example in English is the best proof for how sharp and smart to use a word instead of another to correct the meaning and vice versa. Al Ghaddafi, the former Libyan president was known for giving very long speeches in LLL and uses lots of figurative metaphors such as irony and sarcasm. In his 
speech on Feb $22^{\text {nd }}$ and in accordance with what said, any translator of other nationality than Libyans shall be frustrated because of words intended meaning by the Libyan president.

For instance, during their speeches, Ghaddafi used the third person about 18 times to exhibit his pride in being Muammar Ghaddafi, his status and importance and to praise himself. Consider the following example.

أما اليوم عندما تقول ليبيا، يقولك: آه ليبيا! القذافي! ليبيا الثورة

Here in this sentence he almost erased the Libyans from existence as by meaning in English "today whenever you say Libya, they reply: oh Libya! Al Ghaddafi! Libya the revolution! Here in his saying only him exists and no Libyans at all. It is the way Al Ghaddafi demonstrated that he was the creator of the Libyan country and that he was the one who introduced Libya to the world. By doing so, Al Ghaddafi wanted to gain the people's gratitude for all his good deeds, which would eventually lead to his support.

using the pronoun I, is an effective tool to praise oneself, and demonstrate their achievement in political speeches. Surely, both presidents employed this strategy by constantly using the pronoun I, to refer to their achievements. Al Ghaddafi used the pronoun I about 105 times during his speech, to reflect on his achievement and to revolve the speech around him, as seen in the following example:

أنا أرفع من المناصب التي يتقلدها الرؤساء والأبهات، أنا مقاتل، مجاهد، مناضل، ثائر، من الخيمة، من البادية

I am higher than the positions that presidents and pomps take, I am a fighter, struggler, warrior, and revolutionist, from the tent, from the desert.

In this example, the ' $I$ ' was followed by several active participles, which are usually used as an adjective or a descriptive term in Arabic. The English equivalent of it would usually be a noun ending in /-er/ or /-or/, for example, fighter (Ryding, 2005: 103). Al Ghaddafi described himself using his favorite active participles that have always been associated with his name: the fighter, struggler, warrior, revolutionary, from the desert.

According to Cap and Okulska, "the use of the personal pronoun "we" includes the audience. can be used for cohesive purposes, providing a sense of unity not only at the purely textual level but also pragmatically" (2013:306). To Al Ghaddafi, using the pronoun we could have meant to share his revolutionary attitude with the Libyan people to remind them of Libya's history and how they supported him against the corrupt regime. This can be seen in the following example as it clearly illustrates how he highlighted his role as the Libyan savior, to which he saved Libya before, and he is willing to do everything he can to save it again from the rebels. By repeating his achievements, he was trying to gain sympathy and support from the people who supported him earlier and those who knew his role in developing Libya. In essence, he was cleverly reaching out to both older and uneducated people, deceiving them into believing that this uprising was merely an action of corrupted young men.

نحن نحن قاومنا جبروت أمريكا، جبروت بريطانيا، الدول النووية، حلف الأطلسي قاومنا جبروته، لم نستسلم، وكنا صامدون هنا نمانيا

We have challenged the great nuclear countries in the world, and we won and they bowed their heads here.

During the years of his presidency, Al Ghaddafi established a reputation for his long, improvised and often fairly casual speeches, as he joked, criticized, and most importantly showed his willingness to use profanity whenever he sought necessary. One can notice that the degree of profanity used in Al Ghaddafi's speech intended to insult and downgrade the protesters. This is because Al Ghaddafi use of foul language had several messages. First, his great condemnation of and furious attitude towards the rebels. Second, he intended to 
demonstrate his capability of doing or saying whatever he wished to. Third, his narcissistic attitude sought the urge to demonstrate his bravery by cursing the rebels and both Arab and Western countries whom he thought of as conspirators. Consider the following example:

لقبائلهم إذا لعنة الله عليهم تركوا العار لأولادهم إذا عندهم أولاد، تركوا العار لعايلاتهم إذا عندهم عايلات، تركوا العار كان عندهم قبائل

May God curses them, they have ashamed their children if they have any, they have ashamed their families if they have any and ashamed their tribes if they have any. As the above example shows, not only did Al Ghaddafi curse the rebels, but he also shamed them.

He attempted to emphasize how they were paid to betray their countries, tribes, and families, and how he felt furious with them. It is important to realize how the word / العارshame has a bad significance in the Arab region, particularly in Libya due to the tribal nature of the country. Hence, an individual's action might bring shame to the whole tribe and they will be disgraced for life for it.

Therefore, Al Ghaddafi's usage of the word was meant to get the attention of the tribe's leaders to stop their sons from taking any actions that might bring shame to the tribe. Regardless, in order for him not to lose his good relations with some of the tribes whose sons had been demonstrating, Al Ghaddafi claimed that he was quite sure that these actions could only come from people with no families and no tribes. This is clearly evident in the way he later added to his statement "if they have any", and repeated it further whenever he questioned whether they had families or tribes. This might also refer to the fact that those youths were not well brought up, and have no morals, due to the usage of the phrase 'if they have any families', which has a common connotation in the Arab region of how one is not well behaved since they have no family to raise them. The reason why this example is important is that it helps illustrate how Al Ghaddafi intended to smartly doubt the protester's origins by cursing them, claiming that they were poorly mannered and that they had brought shame to their family and tribes.

Besides the said above regarding the word use and the meaning playing according to his internal beliefs and the intended meaning, Al Ghaddafi used the word Aljerdan (الفئران كبيرة) الحجم that mean in English rats, meaning here is not literal he only linked the environment of rats as they live in dark and dirty places, so he figuratively used the word to describe any of Libyans whom against him. Another word he used when describing the Islamists as are bearded Islamists with those who are full of lice as lice live in hair.

\section{Recommendations}

Based on the results provided in the current study, the researchers would suggest important recommendations that might help in developing the learning and translation of figurative vernacular in a way that encourages professional translators as well as novice translators to build up general awareness of vernacular language when translating to English. To maximize the benefits of these recommendations, the recommendations in this study would go gradually, first, for teachers and students, and, second, for novice and professional translators. Nearly all speeches he delivered throughout his rule were full of metaphor and figurative words and it is recommended that such speeches should be studied in the aspects of language and Critical Discourse Analysis to add to the translation field more understanding in dealing with a metaphor, simile and figurative language wither classical or vernacular languages. 


\section{References}

Abdul-Latif, E. (2012). Hrwb blāghī-a: Mnāwārāt Khțāb al-slț-a fī sāḥt al-thwrā-a [Rhetorical Battles: Maneuvers of Presidential Speeches in the Revolutionary Arena] Journal of Comparative Poetics, 32, 283-311.

Bahaa-eddin, A. H. (2011). Literary translation: Aspects of pragmatic meaning, Newcastle upon Tyne: Cambridge Scholars Publishing.

Bani-younes, M. A. (2015). Cultural and Sociolinguistic Issues in English-Arabic Translation of Collocations. Studies in Literature and Language, 10(6), pp.53-58.

Banikaelf, A., \& Bataineh, K. B. (2017). A Sociolinguistic Study of Speech Act Realization Patterns in Jordanians' Facebook Status Updates. International Journal of Linguistics, 9(3), pp.264-283.

Banikalef, A., Marlyna, M., \& Ashinida, A. (2014). Linguistic Analysis of Humor in Jordanian Arabic among Young Jordanians Facebookers. AWEJ, 5(3), pp.304-318.

Belloc, H. (1959). On Transilation. The Bible Translator, 10(2), pp.83-100. Cordaro, D.T. et al., 2018. Universals and cultural variations in 22 emotional expressions across five cultures. Emotion, 18(1), p.75.

Campbell, H. (2013). Nato's Failure in Libya: Lessons for Africa. South Africa: Africa Inst of South Africa.

Fairclough, N. (1992). Discourse and Social Change. Cambridge: Polity Press. Fairclough, N. (1995). Critical Discourse Analysis the Critical Study of Language. London: Longman.

Hodge, R., \& Kress, G. (1979). Language as Ideology. London: Routledge Hodge, R., Hodge, R. I. V., \& Kress, G. R. (1988). Social Semiotics. New York: Cornell University Press.

Hatim, B. (1997b). The Translator as Communicator. London and New York: Routledge.

Hatim, B., and Mason, I. (1990). Discourse and the Translator. London and New York: Longman.

Khatib, L., \& Lust, E. (2014). Taking to the Streets: The Transformation of Arab Activism. Baltimore: Johns Hopkins University Press.

Kress, G. (2010). Multimodality: A social semiotic approach to contemporary communication. Routledge.

Mahdi, A. L. A. M. (2009). Metonymy in English and Arabic. for humanities sciences al qadisiya, 12(1), 7-20. Pennycook, A. (1994). The politics of Pronouns. ELT journal, 48(2), 173-178.

Mehran, \& Farsian. (2016) Theoretical Foundations of Translation Studies, International Journal of English Linguistics; Vol. 6, No. 7; 2016, ISSN 1923-869X E-ISSN 1923-8703, Published by Canadian Center of Science and Education.

Ronningstam, E. (2005). Identifying and understanding the narcissistic personality. Oxford University Press.

Ryding, K. C. (2005). A Reference Grammar of Modern Standard Arabic. Cambridge University Press.

Shamaa, N. (1978). A Linguistic Analysis of Some Problems of Arabic to English Translation. Unpublished doctoral thesis, Oxford University.

Wodak, R. (2009). The Discourse of Politics in Action: Politics as Usual. UK: Palgrave Macmillan. 